\title{
TINHA UMA TRADUÇÃO NO MEIO DO CAMINHO Marília GARCIA
}

"Traduzir só é traduzir quando é laboratório de escrita." Henri Meschonnic (2010, p. 269)

RESUMO: A tradução tem sido pensada em vários momentos como parte integrante do processo de formação cultural de determinadas sociedades, como a pedra no meio do caminho que possibilita a abertura para o outro. O presente trabalho busca ler brevemente alguns casos na literatura brasileira em que é possível perceber uma relação de troca com o outro: Oswald de Andrade com Blaise Cendrars, Régis Bonvicino com Michel Palmer, Rafael Mantovani com Adília Lopes. Propõe-se pensar essa relação menos como influência do que como simultaneidade e deslocamento.

PALAVRAS-CHAVE: poesia brasileira; modernismo; poesia contemporânea; tradução; intertextualidade.

${ }^{1}$ Doutora em Literatura Comparada (UFF), com pós-doutorado em Tradução / Letras Neolatinas (UFRJ). 


\section{IL Y AVAIT UNE TRADUCTION AU MILIEU DU CHEMIN}

RÉSUMÉ: La traduction est pensée à plusieurs reprises comme partie intégrante du processus de formation culturelle de certaines sociétés, comme la pierre au milieu du chemin qui permet l'ouverture vers l'autre. Le présent travail cherche lire brièvement quelques cas de la littérature brésilienne dans lesquels il est possible d'apercevoir une relation d'échange avec l'autre : Oswald de Andrade avec Blaise Cendrars, Régis Bonvicino avec Michel Palmer, Rafael Mantovani avec Adília Lopes. Nous nous proposons de penser cette relation plutôt comme simultanéité et déplacement que comme influence.

MOTS-CLÉS: poésie brésilienne, modernisme, poésie contemporaine, traduction, intertextualité.

\section{A TRADUÇÃO NO MEIO DO CAMINHO}

Pelo menos desde o século XVI, quando a língua alemã ganhou uma importante tradução da Bíblia por Lutero, o ato de traduzir tem sido compreendido como parte integrante do desenvolvimento cultural de determinadas sociedades e, mais ainda, como constituinte da própria noção de identidade nacional. Nas palavras de Antoine Berman (2002), a tradução passaria a ser vista como uma atividade que compõe a Bildung, processo de formação cultural. No livro A prova do estrangeiro, o teórico francês analisa a significação histórica da tradução luterana, que se tornou a primeira e decisiva autoafirmação do alemão literário, e destaca o gesto de Lutero diante da tarefa: ele não faz uma opção metodológica pelo sentido ou pela letra, pela liberdade ou pela literalidade, mas mantém uma reflexão aguda sobre a tradução, dando a ver que a problemática cultural ultrapassa qualquer metodologia. Lutero busca fixar uma língua alemã, atento aos usos dos falantes nativos, à oralidade, ao ritmo e sonoridade da língua; por outro lado, não deixa de voltar ao original hebraico (bem como às versões grega e latina) para lidar com o literal, incorporando estrangeirismos quando necessário. Se por um lado, ele trata de germanizar os textos sagrados, que até então eram cheios de latinismos, por outro, o objetivo religioso da Reforma leva-o a manter o literal quando avalia que pode ser um ganho (BERMAN, 2002, p. 49-50). Berman afirma que, neste gesto, 
Lutero percebe as "aporias fundamentais da tradução" avaliando o que "é possível e necessário fazer em determinado momento histórico" (id. p. 62)

A partir deste trabalho, que está nas bases da tradutologia moderna, pode-se compreender por que a tradução na Alemanha é vista como criação, transmissão e expansão da língua. Num movimento diferente do da língua francesa, que durante séculos manteve a tradição das "belas infiéis" - as traduções adaptadoras - a tradição alemã buscou manter uma abertura para o outro por meio da tradução e da incorporação de elementos estranhos à sua cultura.

No caso da literatura brasileira, que consiste em uma literatura mais recente e em constante diálogo com outras literaturas, torna-se uma tarefa ética pensar a tradução como elemento de formação. Nesse sentido, são diversos os termos usados para pensar o gesto de traduzir como procedimento de apropriação: canibalismo, antropofagia transfusão, transcriação. Em diferentes épocas, a abertura para o outro constitui não um fim, mas o próprio meio, a pedra no meio do caminho integrante do processo de formação cultural e tal processo ocorre a partir do posicionamento diante de uma série de heranças e de trocas com o outro: herança de uma língua, de uma literatura e de uma cultura. Quando Oswald de Andrade descobre o Brasil num ateliê em Paris e volta para tentar fundar uma espécie de marco zero do movimento ou quando Mario de Andrade afirma ter, enfim, escapado dos franceses para construir a sua nação, entendemos a aporia que está jogo neste posicionamento: somos formados a partir da herança, mas é preciso se libertar da dívida que traz esse legado e partir para transformar a herança ou semelhança em diferença, isto é, partir para a leitura crítica, incorporando, ao nosso modo, a pedra no meio do caminho, pois, afinal, ela é constituinte do caminho que se desdobra.

O próprio conceito de antropofagia como desenvolvido pelos modernistas traz a ideia de assimilar o que vem de fora e mesclar com os elementos do país, o que contribuiria para a formação de uma identidade. A imagem do antropófago possibilita visualizar esta relação com a tradução, e aqui utilizo o termo tradução já de forma mais ampla, não somente interlinguística, mas intralinguística e intersemiótica, para usar os conceitos de Jakobson. No caso de Oswald de Andrade, é possível pensar em suas traduções e colagem feitas sobre o português dos cronistas da época da colonização (tradução intralinguística), ou em suas releituras dos movimentos modernistas europeus, como o cubismo (tradução intersemiótica).

Outro momento em que houve um trabalho de tradução sistemática de poesia foi a partir da década de 1950 com os poetas concretos. Aproximando-se do ponto de vista de Ezra Pound, um dos maiores tradutores e teóricos da tradução, que reivindica a categoria estética da tradução como criação e crítica, Augusto e Haroldo de Campos realizam um amplo trabalho de tradução defendendo a teoria da transcriação, ou da tradução criativa, segundo Haroldo de Campos. Ecoando a máxima de Pound, eles justificavam seu trabalho incessante de vertedores de outras poéticas afirmando que "uma grande época literária é sempre uma grande época de traduções, ou a segue" (apud CAMPOS, 1992, p. 35). Deste modo, eles 
tinham em mente a incorporação de procedimentos e vozes que pudessem agir criticamente sobre a sua época. Pode-se ler na própria escrita de Haroldo de Campos a incorporação de algumas de suas traduções (em Galáxias, por exemplo, texto que trabalha com a escuta de muitas vozes), transformando muitas vezes o exercício tradutório em prática de escrita. As traduções feitas nesta época produziram uma pletora de desdobramentos não somente no momento mais militante do grupo, como também posteriormente, já que seguiram com o trabalho e com a reflexão em torno da tradução. Para citar um desses desdobramentos, há o artigo publicado nos anos 1980 da poeta Ana Cristina Cesar (que também praticou a tradução como exercício de escrita), em que analisa os caminhos percorridos pela tradução de Augusto de Campos do poema "Elegia”, de John Donne, que foi musicada por Caetano Veloso no final dos anos 1970 e, ao alcançar/produzir esse espaço, em um contexto específico de circulação, o poema adquiriu um sentido não só de projeto estético de divulgação de uma obra estrangeira, mas, também, de constituição de identidade (CESAR, 1999, p.235).

Partindo desses caminhos, assinalo brevemente alguns casos em que parece haver cruzamentos desse tipo, isto é, em que ocorre na escrita a utilização de procedimentos que parecem derivar do diálogo com o outro. Em cada um deles, gostaria de pensar menos numa relação de influência do que de simultaneidade. Proponho pensar na ideia do simultâneo a partir de uma imagem do crítico francês Georges Didi-Huberman acerca dos termos Simultâneo e similar. Segundo ele, ambos

possuem a mesma raiz do latim, simul, que significa algo como rivalidade na sorte: três dados são lançados, três dados absolutamente similares que caem ao acaso, ao mesmo tempo. Mas vão definir, projetar de imediato três números, três destinos absolutamente diferentes, rivais em certo sentido, entregues à sorte e à sua crueldade. São lançados no mesmo instante, similarmente. Mas uma vez executado o lance, tudo se separa, os abismos se abrem infinitamente. (DIDI-HUBERMAN, 2009).

Assim, poderia ler nesses cruzamentos não uma relação hierarquizada de fonte e influência, mas procedimentos similares que entram no caminho de línguas diferentes e, em cada uma delas, produz conexões díspares. Dependendo do caso analisado, é possível dizer que os procedimentos estavam no espírito do tempo, sendo assim similares, lançados na mesma época em línguas e contextos diferentes.

A blaise CENDRARS, POR OCASIÃo dA DEScoberta do BRASIL 
Começo lembrando a relação estabelecida dos escritores modernistas com Blaise Cendrars. Em 1924, na chegada do franco-suíço ao Brasil, Mario de Andrade faz a seguinte declaração:

Na poesia, si fôra servil, mesmo torpe imitarmos Blaise Cendrars, é certo que o exemplo dos seus poemas nos facilitará a criação da poesia livre, forte, vibrante, audaz e colorida que tem de ser a da nossa raça em formação. Porque se a nossa raça não for livre nem vibrante audaz e colorida será faltamente melancolizada pela incompreensão da própria terra [...] Cendrars me libertou da incompreensão do passado [...] Livrou-me do ritmo impessoal, dando-me, não o seu, mas o meu ritmo (...) Foi Cendrars que me revelou o conhecimento. E, poeta francês, livrou-me da França. (ANDRADE, 2001)

É surpreendente a declaração de Mário pelo tom de gratidão ao autor de $A$ prosa do transiberiano e também pela menção à descoberta de si a partir da apropriação do outro. Tal depoimento se assemelha ao de Manuel Bandeira que, em 1957, declara sua dívida ao cotidiano prosaico de Cendrars (apud COSTA LIMAEm uma leitura acerca das trocas entre Cendrars e Oswald de Andrade, Luiz Costa Lima aponta três características similares na escrita dos dois: 1 . o uso que fazem da linguagem coloquial, 2. o tom sintético, seco e rápido das duas escritas, e 3. o uso do corte e da justaposição, criando uma descontinuidade bem própria às vanguardas da época (COSTA LIMA, 1991, p. 191). Os três procedimentos seriam fundamentais para os desdobramentos do modernismo brasileiro e estão presentes no prolífico diálogo entre Cendrars e Oswald. Não se trata aqui de identificar quem influenciou quem ou hierarquizar a troca, apontando uma provável influência de Cendrars, deduzida dos depoimentos e de sua obra anterior à chegada ao Brasil. Cabe mencionar também que considero neste ponto não as traduções dos poemas, afinal não localizei textos do Cendrars traduzidos pelos modernistas; quando Oswald ou Mário citam Cendrars, fazem-no em francês. Mas trato aqui, sobretudo, da tradução de procedimentos. Cendrars e Oswald mantinham à época uma relação tão próxima que Oswald lhe dedicou seu primeiro livro de poemas, Pau-Brasil (impresso em 1925, com o prefácio de Paulo Prado assinado com a data de 1924): "A Blaise Cendrars por ocasião da descoberta do Brasil" (ANDRADE, 1966). Cendrars havia "descoberto" o Brasil em 1924, tendo vindo de navio e passado vários meses em contato direto com os modernistas. Seu livro Feuilles de route mostra certa consonância com o PauBrasil, não apenas no que diz respeito às descrições da viagem ou à descoberta do país, mas ao tom, ao modo, aos cortes. Oswald propõe a sua própria descoberta recuperando a língua do início dos cronistas portugueses, mas também registrando a fala cotidiana atual, elemento recorrente em Cendrars. 
Por outro lado, segundo Haroldo de Campos, a câmera portátil dos poemas oswaldianos tinha um dispositivo que não estava presente na kodak excurcionista com que Cendrars fixou suas fotografias verbais brasileiras: a visada crítica. (CAMPOS, 1966, p. 34-5). Ao olhar para si mesmo com os óculos do outro, ele poderia transformar o filtro em leitura crítica de si e, assim, ultrapassar o que era apenas exótico nos instantâneos turísticos cendrarsianos. Em cada poética, o procedimento se desdobra de uma forma.

Sabe-se também que a metáfora antropofágica desenvolvida pelos modernistas traz em seu ponto de partida essa abertura crítica para o outro: os índios canibais não devoravam qualquer um; os candidatos à devoração precisavam, antes, dar provas de suas qualidades, pois os índios acreditavam adquirir as características do devorado. Assim, o conceito possui mecanismos e formas ligadas aos processos de intertextualidade e à noção de tradução crítica, em que se apropria de qualidades específicas do outro para estabelecer novas conexões. Em seu texto sobre o poema pós-utópico, Haroldo de Campos observa que o único resíduo utópico que restou no presente é a dimensão crítica e o dialogismo que devem nele permanecer (CAMPOS, 1997, p. 269).

\section{DIÁlOGO DE RISCOS MÚTUOS}

Pensando num caso recente, cito um livro de 2001 Cadenciando-um-ning, um samba, para o outro que encena claramente o jogo com o outro sugerido no título. Contribuem para essa sugestão o subtítulo da obra (que diz poemas, traduções, diálogos) e a dupla assinatura, de Michel Palmer e Régis Bonvicino. O livro é composto de poemas de Palmer traduzidos por Bonvicino e traz também vários paratextos como entrevistas e uma seção denominada "outros diálogos", com ensaios e poemas de outros autores, como os da série em torno das "Autografias" de Palmer, que apresenta poemas do francês Claude Royet-Journoud, de Mario de Andrade e, ainda, um poema do próprio Bonvicino. Esses últimos poemas recebem uma numeração (por exemplo, a Autobiografia de Mario de Andrade - que é o poema "Paisagem 3" - é a de número 14, remetendo para o poema de Palmer de mesmo número que cita o autor paulistano). Assim, a conversa tem mão dupla, já que nos anos 90, Michel Palmer visitou São Paulo e parte dos poemas publicados neste livro se refere à cidade: ele fala de pessoas que conheceu nessa viagem, como Arnaldo Antunes, de situações vividas ali e mesmo de autores que leu, como o próprio Mario de Andrade ou Leminski, citando seus versos. Em nota que abre o livro, Bonvicino explica que não vê seu trabalho como "tradução", mas como um "diálogo de riscos mútuos" já que os originais e traduções haviam sido feitos quase simultaneamente (PALMER; BONVICINO, 2001) e este é um critério também para a escolha dos livros a serem traduzidos, pois ele selecionou poemas que estivessem dentro do espectro dessa escrita simultânea. Aqui a imagem de Didi- 
Huberman citada acima retorna para a nossa leitura: procedimentos similares entram no caminho de línguas diferentes simultaneamente. Em cada uma delas produzirá conexões díspares e desdobramentos próprios.

Além do livro de Michel Palmer, seria possível ler outros projetos similares do tradutor - como, por exemplo, o livro de Robert Creeley publicado no Brasil em 1997. Mas neste caberia pensar em outros aspectos como, por exemplo, se os poemas selecionados para a antologia não teriam sido escolhidos justamente por apresentarem elementos próximos de certa dicção dos anos 1990 na poesia brasileira, da qual Regis Bonvicino é um dos protagonistas.

\section{LANCE DE DADOS SIMILARES E SIMULTÂNEOS}

Em uma entrevista, o escritor Rafael Mantovani, que também é tradutor, declarou que escrevia seu novo livro buscando dialogar com a polonesa Wislawa Szymborska, recém-publicada no Brasil (2011). Ao ler um dos poemas de Mantovani em que ele dizia constituir um diálogo com a autora, outra presença que não a de Wislava me chamou a atenção ali e pude confirmá-la dentre as eleições do autor ao reler seu livro, de 2011, chamado Cão, que trazia referência explícita à portuguesa Adília Lopes. A primeira parte do livro não só apresenta uma epígrafe dela, como também um poema chamado "Adília Lopes" e outros dois onde ela aparece citada como um modo de leitura: "à maneira de Adília Lopes" (MANTOVANI, 2011, p.41) e "também à maneira de Adília Lopes" (idem, p. 46), recurso, aliás, bem presente na escrita de Adília, que multiplica os asteriscos indicando suas referências.

Além desses traços explícitos que nos levam até Adília, há vários ecos da portuguesa presentes no livro, seja nas discussões de gênero (para citar um único exemplo, a primeira parte do livro se chama "Coa", que segundo o autor seria um neologismo para designar o feminino de "cão"), seja na presença de personagens do seu universo doméstico, como a mãe, a tia, os amigos que aparecem apenas com o primeiro nome multiplicando a sensação de estarmos no universo da poetisa. Há também um poema "parábola de Ênia Datta" (Id., p. 41) que poderia constituir uma das narrativas de Adília, em que elementos non-sense e de contos de fadas são identificados (como o poema, dela, "Sereia das pernas tortas"). Além desses elementos, há inúmeros jogos de palavras e paronomásias que vão, aos poucos, produzindo novos sentidos na aproximação de seus significantes, e com isso soando irônicos. Como o "cão" do título do livro que vira "coa" que vira "com" que vira "céu" (essas são as partes do livro), que vira "coltrane" e daí por diante. Para completar, o recurso da série está bem presente nos poemas em que identificamos um tom e um corte que remeteria ao universo de Adília e a forma como ele usa esse recurso nos remete também ao diálogo assinalado. Como no poema "deixados e perdidos" (Id., p. 46), onde cada parte da série lista objetos e pessoas dei- 
xados e perdidos, brincando com a expressão habitual "achados e perdidos" e provocando certa instabilidade pela falta incontornável no duplo que seria habitual.

Há dois aspectos que tornam este diálogo com Adília Lopes ainda mais interessante. Em primeiro lugar, há que considerar o impacto que tem causado sua obra no Brasil desde que foi publicada em livro aqui (este impacto dentro do mínimo que é a edição e circulação de poesia, claro). Em 2002, saiu o livro Antologia e desde então a referência a ela é crescente. O livro teve recepção não somente na área de literatura portuguesa, para quem Adília já era conhecida, mas também dentre os outros leitores de poesia. Não passam desapercebidas as muitas citações a ela, de poemas a entrevistas que a mencionam chegando a vários trabalhos acadêmicos e ensaios dedicados à autora, bem como livros que apresentam procedimentos presentes também em sua escrita. ${ }^{2}$

Já o segundo aspecto que gostaria de mencionar refere-se ao fato de Adília Lopes ser portuguesa, ou seja, escrever em português e entrar aqui sem precisar de uma tradução interlingual. Voltando à imagem de Didi-Huberman, no caso de Adília podemos pensar o lance de dados similares e simultâneos de forma literal: ao ser lançada na literatura brasileira hoje, Adília estabelece conexões bem diversas das que tem em Portugal. Se houve em geral no Brasil uma tentativa de distanciamento da literatura portuguesa, é curioso pensar que hoje uma autora como ela possa ser lida como se fosse uma tradução e produzir deslocamentos inesperados. Uma hipótese rápida para essa recepção poderia estar na identificação de certos traços da escritora com um tipo de poesia modernista. Talvez sua diç̧ão apresente certa familiaridade para o leitor brasileiro e possa apresentar alguns desdobramentos, caminhos e soluções que ainda não foram trilhados aqui.

Voltando ao livro de Rafael Mantovani, gostaria de ler uma imagem que atualiza a ideia de apropriação do outro, de pedra no meio do caminho que acaba sendo incorporada no processo:

\author{
Adília Lopes tem poemas \\ tão simples \\ que não entendo \\ de tão finos não consigo \\ entrar
}

\footnotetext{
${ }^{2}$ Outra autora que poderia lembrar aqui é Angélica Freitas, cujo livro de estreia, Rilke Shake, de 2007, e o seguinte, Um útero é do tamanho de um punho, trabalham não só com paronomásias e repetições mas também com pequenas histórias que refazem fábulas e jogam com clichês, além de tocar no tema do feminino. Desconheço se essa relação de Freitas com a portuguesa é analisada em outro lugar, mas gostaria de citar a pesquisa de mestrado em andamento de Eduarda Rocha, desenvolvida na Universidade Federal de Alagoas, "Trânsitos poéticos entre Brasil e Argentina: uma leitura de Angélica Freitas e Susana Thénon”, em que a pesquisadora analisa a relação de Angélica Freitas com a escritora argentina Susana Thénon, que ela traduz para o português. A pesquisa busca ler a incorporação de temas e procedimentos da poesia de Thénon em sua própria escrita.
} 
porque saio do outro lado.

(MANTOVANI, 2011)

Não conseguimos entrar no poema (talvez porque neste caso nem seja preciso "entrar" para traduzir, por exemplo), mas de algum modo, ao deparar com ele, saímos do outro lado, tendo incorporado a experiência (mesmo que seja da incompreensão) e passado pelo deslocamento.

\section{A TRADUÇÃO COMO LABORATÓRIO DE ESCRITA}

Por fim, um relato de uma experiência pessoal. E retomo a epígrafe de Henri Meschonnic sobre a tradução como laboratório de escrita. Em 2006, traduzi um poema longo chamado "Dois andares com terraço e vista para o estreito" (HOCQUARD, 2008), do escritor francês Emmanuel Hocquard. Trata-se de um texto que narra uma viagem a Tânger, cidade em que o autor passou sua infância $\mathrm{e}$ juventude. Ele é construído com vários planos, compaginando memória, linguagem e deslocamentos, espécie de poema-percurso que caminha com o desenrolar do texto. Essa narrativa é feita a partir do encontro de várias vozes dos personagens que vão passando e, como é um texto sem pontuação nenhuma, muitas vezes não sabemos quem está falando. Dentre as dificuldades de tradução, havia algumas ligadas ao campo semântico do texto que remetia à origem do autor: francês, ele cresceu no norte da África, convivendo de perto com o neocolonianismo e com aspectos especificamente árabes e marroquinos; além disso, havia também dificuldades ligadas à tradução do francês para o português, como por exemplo, a questão pronominal: o que fazer com os pronomes que definem com tanta precisão em francês e que não podem ser levados para o português sem certo desconforto ou contorcionismo? Como o poema trazia um forte tom coloquial, a questão pronominal era ainda mais incômoda, pois dificultava o ritmo em português.

A primeira versão da tradução foi, de fato, um laboratório de escrita e me trouxe ferramentas para a segunda "tradução" que fiz, em 2009, numa viagem para conhecer o autor. Nesta viagem, decidi que escreveria um texto com o mesmo tom do poema de Hocquard: este seria também um "poema-percurso" narrando uma viagem e me apropriaria de alguns versos e frases dele. A minha viagem não seria para Tânger, como a do poema dele, mas para Mérilheu, cidade no sul da França onde Hocquard vive. Ao chegar lá, ele me disse "Sua viagem a Tânger será aqui" e foi assim que escrevi o Engano geográfico, publicado em 2012, que poderia ser lido como uma tradução alternativa do "Dois andares com terraço e vista para o estreito".

Além de incorporar o tom de distanciamento que o poema dele usa para tratar de um reencontro com uma cidade que lhe é tão cara, também recortei alguns versos e sobrepus espaços e temporalidades. E fiz um jogo pronominal que não equivale a uma "tradução" do que está no poema, mas busca evidenciar a dificuldade da tradução dos pronomes fazendo explodir a ambiguidade em português. Em outras pala- 
vras, busquei multiplicar o mal estar que temos ao traduzir os pronomes para o português - seja porque não exista uma regra definida quanto ao uso pronominal, principalmente em situações coloquiais, seja porque não temos alguns dos pronomes da língua francesa, como o "y" e o "en". Apesar da precisão do francês (sobretudo no que diz respeito aos pronomes que definem os "quems" da história), o poema de Hocquard é composto por várias vozes que vão conduzindo a narrativa e que se alternam, muitas vezes sem mediação. No Engano geográfico busquei multiplicar esse exercício coral com um jogo pronominal possível em português (ocultando os pronomes, por exemplo) que tornou ainda mais ambígua essa estrutura.

\section{REFERÊNCIAS BIBLIOGRÁFICAS:}

ANDRADE, Mario. "Blaise Cendrars". In: Eulálio, Alexandre. A aventura brasileira de Blaise Cendrars. São Paulo: Edusp, 2001.

ANDRADE, Oswald. Poesias reunidas. São Paulo: Difusão Europeia do livro, 1966.

CAMPOS, Haroldo de. "Por uma poética da radicalidade.” In: Andrade, Oswald.

Poesias reunidas. São Paulo: Difusão Europeia do livro, 1966. . “O poema pós-utópico.” In: O arco-íris branco. Rio de Janeiro: Imago, 1997.

"Da tradução como criação e como crítica". In: Metalinguagem e outras metas. São Paulo: Perspectiva, 1992.

CANDIDO, Antonio. "Os primeiros baudelairianos". In: A educação pela noite. Rio de Janeiro: Ouro sobre azul, 2011.

CESAR, Ana Cristina. "Pensamentos sublimes sobre o ato de traduzir". In: Crítica e Tradução. Rio de Janeiro: Instituto Moreira Salles, 1999.

COSTA LIMA, Luiz. “Oswald, poeta”. In: Pensando nos trópicos. Rio de Janeiro: Rocco, 1991.

CREELEY, Robert. A um. São Paulo: Ateliê editorial, 1997.

DIDI-HUBERMAN, Georges. "Similar e simultâneo". In: Revista modo de usar \& co. 2. Rio de Janeiro: Berinjela, 2009. 
GARCIA, Marília. Engano geográfico. Rio de Janeiro: 7letras, 2012.

HOCQUARD, Emmanuel. "Dois andares com terraço e vista para o estreito". In: Inimigo Rumor 19. São Paulo: Cosac Naify, 2008.

LOPES, Adília. Antologia. São Paulo: Cosac Naify, 2002.

MANTOVANI, Rafael. Cão. São Paulo: Hedra, 2011.

MESCHONNIC, Henri. Poética do traduzir. Tradução de Jerusa Pires Ferreira e Suely Fenerich. São Paulo: Perspectiva, 2010.

PALMER, Michel; BONVICINO, Régis. Cadenciando-um-ning, um samba para o outro. São Paulo: Ateliê editorial, 2001. 